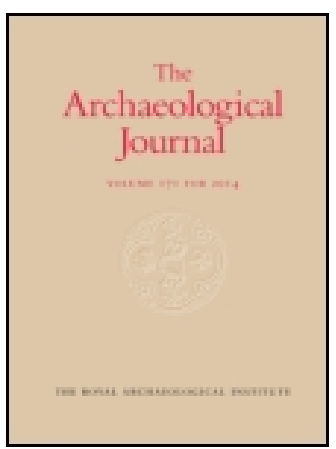

Archaeological Journal

\title{
Note on a Boat Found at Albert Dock, Woolwich
}

\section{F. C. J. Spurrell}

To cite this article: F. C. J. Spurrell (1890) Note on a Boat Found at Albert Dock, Woolwich, Archaeological Journal, 47:1, 170-170, DOI: 10.1080/00665983.1890.10852422

To link to this article: http://dx.doi.org/10.1080/00665983.1890.10852422

曲 Published online: 15 Jul 2014.

Submit your article to this journal 주

View related articles 


\title{
NOTE ON A BOAT FOUND AT ALBERT DOCK, WOOLWICH. ${ }^{1}$
}

\author{
BV F. C. J. SPURRELL.
}

In 1878, while excavating the mound for the construction of the Albert Dock at North Woolwich on the Thames a boat was found in fairly good preservation. Its situation with respect to the soils in which it lay and its peculiar shape make it worthy of description. In a former account, I described the surface of the upper layer of peat, or more properly the ancient ground on which trees grew in abundance, as the surface of land on which the Romans lived and died; at this very spot.

Now, I exhibit a section of the ground shewing that in the peat layer a stream (freshwater) had excavated a small channel; that this stream was accustomed to carry boats is evident, because in its own mud and not in the peat itself, a boat was found. The surface of the peat was the shore of that day, and the existence of the stream must have belonged to the later part of the period which was occupied in the accumulation of the trees' growth and their debris. Therefore the stream was apparently in full run about 1700 years ago. And the boat apparently belongs to that age. Since the boat was lost the deposit of tidal mud had almost obliterated any sign of the channel.

The "dug out" or canoe is of oak, in a single piece and free from knots. It was carefully worked and no sort of clumsiness can be detected in its form. The form is regular and was evidently planned to measure. The dimensions I give are probably less than the original ones, because they were not taken until the boat was nearly dry, and considerable shrinkage has since distorted the partially decayed wood, the whole being somewhat lessened, and the contraction of the thicker masses tearing the thinner parts asunder. All the originally clean lines of the carpenter have also saffered considerably.

The extreme length from bow to bow (for both ends are, or were, exactly alike) was 17 feet, the width outside abeam between 24 and 25 inches, which was all the same with the exception of the last 12 inches of either end ; these sloped inwards 8 inches, the end being not rounded but straight and 8 inches wide.

The bottom was flat and the sides also, and rectangular. The thinnest part of the sides is little more than half an inch above, nearly three inches below where it unites with the bottom. The bottom thins to less than two inches at the middle. There is a peculiar arrangement at each end, perhaps constituting a raised seat. There is no keel, no ribs or stretchers at the bottom, and no marks for rowlocks. But no paddles were found. The boat is now in the British Museum.

1 Read at the Monthly Meeting of the Institute, Dec. 6th, 1888. 